\title{
INTELLIGENCE AND SOCIAL LIFE
}

\author{
H. E. CUNNINGHAM \\ University of Oklahoma
}

\begin{abstract}
Intelligence, the only hope of an organized future, should be redefined in the light of present problems.-Each age defines intelligence in the light of its own problems. Examples of this are seen in $(a)$ periods of social breakdown when the world is drifting away from the individual and society, and when recourse is taken to the world of inner experience, to the detriment of progress in the world; and $(b)$ in periods in which the intellect is at home in the world of science. It is this second attitude which offers hope for the future, although our day is marked by the opposite tendency.

The place of intelligence in contemporary systems of philosophy. - A short examination of the philosophy of empiricism, idealism, the new realism, and mysticism, as each states the nature and function of intelligence, reveals the fact that they offer little or no hope for social reconstruction. The biological or instrumental view, however, is suggested as one which offers hope for a more stable future.
\end{abstract}

It is fitting that theories of philosophy which have been built in the presence of a given set of conditions canvass their principles in the light of phenomena which, by the very nature of the case, the principles as originally formulated did not contemplate. A theory of reality, knowledge, or conduct which had its origin in an environment of peace, in a period of rapid scientific advancement, and in an age of commercial exploitation must of necessity reflect the general nature of such a period; and in the presence of a different social and physical background such a theory is likely to appear obsolete. Philosophy today cannot escape the rapid "socialization" which is occurring in all departments of human interest; it should have something to say in the conflicts about us unless it is become either a mysterious pursuit engaged in by a select group of intellectual high priests, or a refuge for a weary soul.

One of the most important messages philosophy has to deliver to the world is that of the nature and function of intelligence in human experience. In the light of present facts of a social, political, and economic nature what theory of intelligence will offer hope for a clearer and saner future? 
Intelligence is characterized by the ability to vary the type of response which a given situation may provoke. Variability in responses indicates a non-mechanical, non-habitual, and noncustomary mode of behavior. And it is through variation that all advance, scientific, religious, political, occurs. Thus considered, intelligence has a definite set of functions to perform in the social life of a people.

When intelligence is regarded as an end, some form of aristocracy is the result in which the favored few are set off "from the crowd's ignoble strife." When it is conceived as a force in the world which realizes itself in institutions by means of the overcoming of contradictions, the result is a form of fatalism which may well be summed up in the sentence of a modern poet: "God's in his heaven, all's well with the world." When, as in the philosophy of the new realism, it is a neutral entity or the cross-section of the environment or something that gazes charmedly on the unwindings of a set of indefinables, it becomes a worn-out shell with nothing to do in shaping affairs politically or otherwise. It may be viewed as a registering machine, as indeed it was in the philosophy of Bentham and the Mills, and when so conceived it becomes wholly passive, a doctrine of association arises, and all reforms are based on changes in the physical environment. There are other conceptions, among which is that which denies to intelligence any creative function whatever, and which results in the apotheosis of faith and the mystical participation in a supermundane reality.

Each of these views of intelligence has flourished in the history of philosophy, each a reflection of the social life, interests, and problems of a period; and each leading to a more or less welldefined program of practical politics, moral theory, and philosophy of science.

When intelligence "comes from afar" we may be pretty sure that the chief things of value are not of this world, but that man lives and moves and has his real being in a different sphere from that in which our problems actually flourish. We may rest assured that authority comes from above downward-from the premise to the conclusion, from the monarch to the subject, from the master to the slave. Whether such a view of intelligence is the result of an 
already existing social and political organization or whether such an idea leads to the latter is not essential, for regardless of precedence and causal connections these views prevail, one in the practical and the other in the speculative activities.

Intelligence comes from afar in those periods of social breakdown when man is a "pilgrim and a stranger here," when he is "seeking a city to come." When man loses control over the forces of his environment, when, that is, some other means of control is substituted for the intellectual, we have that type of political life or religious, depending upon the prevailing social organization, which is conducive to authority from some other than human sources. Bankrupt intelligence and mystic participation in an otherworldly reality are the religious and political concomitants of a decaying social and philosophical life.

The period following the breakdown of Greek civilization is characterized by the numerous doctrines that arose to offer unstable man a "rock in a weary land." Man has always found it necessary to have something to live by, some theoretical framework to orient him in his world of facts, some hypothesis to remove at least in part the strangeness of his journey through this vale of tears. And in the period in question the function of intelligence was to construct a tenable theory of living. A philosophy of inner experience, that haven of rest for a world-sick and tempest-tossed soul, as yet had not been developed; and man was in the century or two before Christ looking upon a physical and social environment which was gradually slipping beyond his control. When his environment had moved wholly beyond his instruments of direction, he had recourse to inner experience and erected mansions unattempted yet in prose or rhyme. "Go on, World, chase your favorite phantom," are the words of the Cynic and the Stoic alike. "Give me pleasure," says the Epicurean, "and little care I what are the facts of the social and physical world." Much intelligence became a weariness to the flesh and a vexation of the spirit for both the Stoic and the Epicurean. It became totally bankrupt in neo-Platonism and subordinate to faith in Christianity. In these latter it came in contact at no point with genuine reality, but like the genial hod-carrier had nothing to do but convey materials to the 
real builder, faith. Throughout the period from the collapse of Greek civilization to the Renaissance intelligence in the main gazed at a world to be controlled by prayer, fasts, and miracles, and not by judgments which lay hold of the raw stuff of experience, which is to be whipped into material which assists in building further a world to be controlled, guided, and directed.

The Romantic movement represents another period of intellectual decay and of emphasis on feeling, poetry, and mysticism. During the four centuries prior a type of intellectual life had flourished, had come to a head, and had broken down in social and political revolutions and in great revivals of religion. Then Tiecks and Schlägels and Schleiermachers and Rousseaus and Wordsworths had their day in the gladsome primordial; then nature lived and was to be fondled; then feeling ran rampant in social, artistic, and moral life; then dreams of liberty, fraternity, and equality were dreamed and expressed in declarations and constitutions; then intelligence, which had a little earlier flourished in the realms of physical and formal astronomy, in optics, physiology, and mathematics, "came trailing clouds of glory from God who is our home." A century or two before morality could be treated more geometrico, and anomalies of the moon were matters of deepest intellectual interest; but in the Romantic period morality ran riot in the feelings, and the moon became the object of worship in poetry as she "Nightly to the listening earth repeats the story of her birth." No longer was the flower to be subjected to cold, intellectual classification as was the wont of Linnaeus, but its essence was expressed more adequately in the nature poetry of the Romanticists.

Such, in brief, is the temper of mind when the world is slipping from under the feet of a people. And it is today fitting that philosophers undertake an estimate of our own period. While it is natural for every age to have believed that that particular one was the greatest in history, and for thinkers of every period to have looked upon their own as one of transition and of deepest significance for the future, it will pass without serious objection that our present period is one in need of careful direction due in part to the many channels opened for the release of hope, desire, and 
interest. We have just witnessed a type of speculation and its concomitant practicality topple over in the onward rush of human experience; another type of theory and practice has come to a head, borne its fruit, scattered its seed, and died.

It is certainly true that the world is getting beyond the control of the individual; no one is large enough to carry a great measure or guarantee the success of a policy; but things are done by groups, leagues, unions, trusts, drives, organizations. We have yet to see whether groups can accomplish such results as will hold the mind of man on the affairs of this world, or whether, failing, we shall again have recourse to that inner world where "Iron bars do not a prison make."

There are grave dangers, however, in over-socialization. It should be remembered that all great principles were once the hope and possession of an insignificant minority, and that progress has always been made by the individual at the point of breakdown between an old theory, hypothesis, or custom, and facts which could not be interpreted in terms of the old. Such advance is possible only in the experience of the individual-he is the focal point of progress and change, the mutant who deviates sufficiently from the norm to carve out new paths for the release of human energies. Over-socialization leads to the same throttling of intelligence, the same strangling of initiative that results from any other form of absolutism. Society can be as autocratic and tyrannical as states and churches have been. Constitutions which have been written for the safeguarding of liberties may be turned into instruments of imprisonment.

The one saving feature of all such overorganized life has been that the rules promulgated for guiding behavior have been and of necessity must be so general that they are not applicable to any particular case, and they leave to the individual the opportunity of exercising his curiosity in the pleasant but useless pastime of determining whether or not his own case falls under the general rules. The stifling thing, however, is that the rules mark out the limits within which the individual may exercise any intelligence whatever.

Our time is marked by a movement toward mysticism and romance. The revival of interest in spiritualism, the hypnotic 
influence of the fact that the individual is a member of the Great Society, and that there appears to be some invisible power, whether state, union, or church, are forces which tend to shift responsibility to a superindividual power, and to remove ultimately the seat of sanctions for conduct to another world.

There is another attitude in the history of intelligence which flourishes in periods of peace and prosperity. Man's attention is then directed to the affairs of this world, science flourishes, commerce and industry enlarge, and great waves of expansion in all lines of human interest occur. Channels are opened which release desire, interest, and hope; man becomes a citizen of this world; his values and his problems are here, and he seeks for their realization and solution in terms of human experience. His prayers become expressions of praise and not lamentations; a God of justice takes the place of a God of love; the forms of religious worship rather than the spirit of it are emphasized; when he prays, "Thy will be done," he actually means that he wants things to remain as they are; and "Thy kingdom come" for him connotes a world of greater opportunities to chase his phantom. This is the period of the birth of the individual; he grows away from his group as he masters the technique for the control of his natural environment, when he no longer needs the direct support of his fellows in his enterprises. In economic, political, and social life the "captain of industry," the "boss," and the "leader" originate. In literature classicism and naturalism prevail; in politics the law of nature becomes free from the law of God, as is witnessed in the movement from Aquinas and Suarez to Grotius-jus naturale is dissociated from revelatio; and in science sweeping hypotheses are projected and are verified or rejected on the principle of their value in accounting for the facts of human experience in the particular field of investigation. Great outward movements, marvelous appreciation of this world and its problems and values are characteristics of this period. Life reaches out from its shell, so to speak, and its tentacles explore all recesses. In such periods intelligence is at home in this world.

But these attitudes represent the atmosphere in which intelligence operates: they do not indicate any of the precise methods by 
which it brings about its results. At the outset several views of the nature and function of intelligence were indicated; and if we wish to express them in terms of philosophic movements we may say that they are the biological or instrumental, the idealistic, the empirical, the realistic, and the mystical respectively. Each view figures in the thought of today as every student of philosophy well knows. It certainly would be rank injustice to attempt to give an adequate view of intelligence as expressed in each of these tendencies, but fortunately such is not our purpose; we are insisting on a recanvass of the contributions of each to determine what may be offered for the solution of problems everywhere about us.

It is in the logic of a system that we may well look for the social implications of that system. Logic displays intelligence as it functions in the process of judgment, the kernel of the technique by which new heavens and new earths are created.

If an idealism which removes ultimate values from this world to another, which sees in the efforts of man the operations of appearances and not reality, which considers the only good the Good Will, which regards all change as a process of self-realization or the realization of an Absolute idea-if such a program will assist in the solution of problems about us, well and good. In the logic of such a system judgments are always partial, and reality is of such a nature that it can never be comprehended by the finite knower, who must be content to beat the thin air of appearances. The net result is that intelligence, through the medium of its operation, the judgment, flounders hopelessly in the seeming-invain efforts to reach the Holy Grail of an Absolute Mind.

The logic of empiricism, best expressed in the works of John Stuart Mill, presents difficulties equally serious. We might pass over them without mention with the solacing thought so well expressed by Mr. Schiller that it is useless to castigate a dead horse, were it not for the fact that the same dead horse finds a place in the practical intellectual activities of the day. Working on the assumption of a given environment, a reflection of that authority which English peoples have so bravely in their practice struggled against, the judgment consists in the presentation to this givèn reality an idea of itself, this idea being a copy of the reality in 
question. It is easily seen that such a view of the judgment can in no way effect a modification of the world or a reconstruction of a chaotic situation.

The realistic or physical and mathematical view of intelligence is the most recent addition to the philosophical household. The certainty of mathematics has always made a strong appeal to men and has led them to attempt to introduce the same rigor into other lines of interest. All views of this nature are difficult in detail but simple in principle. The logic of the modern rationalistic movement is, briefly, that a few active indefinables somewhat like unto the atoms of Leucippus and Democritus, somehow "start" in the world (not in the "world" as we know it) and in some manner determine a universe. Now human intelligence has as its purpose the unearthing of these dynamic entities by the method of analysis or internal scrutiny, and on the emotional side to dissipate itself in the capacity of a charmed spectator at the diverse ways these entities take their wonders to perform. Judgments are mere expressions in symbols of what is discovered, neither adding to, nor subtracting from, true reality, which is always a complication of some of the indefinables. In both idealism and new realism human intelligence is impotent, in the one dealing with appearances, in the other a trailer of aggressive indefinables. The same may be said of empiricism and mysticism-in the former intelligence registers the facts of an objective environment, in the latter it has utterly surrendered.

It would be useless to pursue farther the mystical attitude of mind than was indicated in the earlier parts of the paper. As far as reconstruction in the judgment is concerned it has nothing to offer, for it indicates precisely that reconstruction is impossible and that judgments are futile. It represents the attitude so admirably expressed on the great seal of the state of Virginia. In effect it says, "I am down, O World, and your foot is on my neck. What more can be done but to philosophize on the vanity of human wishes?"

From the instrumental standpoint intelligence actually does something; it is conceived as a means in a larger process of experience; it is regarded as a creative energy which operates in at least 
two directions, namely, in the creation of valuable objects in the nature of habits of action, customs, and institutions; and in the creation of the agent who expresses the judgment. In this sense intelligence has as one of its chief purposes the adjusting of conflicting interests, the resolution of counteracting forces, and the resultant creation of a more adequate background in the nature of the character of the one who judges. Judgments occur in a fluid medium and not in a fixed environment either of complicated indefinables or of physical objects; nor yet in one in which an Absolute Mind is realizing itself, or in which chaos so prevails as to paralyze intelligence. On the instrumental view the predicate of the judgment is a tentative program of behavior, the subject is the unquestioned "this" (unquestioned, that is to say, as to its existence, but questioned as to its meaning), the copula is the active, dynamic, try-on process that is present in every live judgment. The result of such a process is a settled mode of action-settled for the present at least-which terminates in habits for the individual, customs for the group, and institutions for the race.

Such a view of intelligence is again advanced as a means of social, political, economic, religious, and scientific reform. It advances the thesis that direction of forces and the resultant creation of institutions and objects of value cannot occur by blind mysticism, nor by obedience to a "given," whether in religion, government, science, or society; nor by gazing on a set of indefinables, or fanning the thin air of appearances; but by diligent and painstaking projection of hypotheses, and verification of them by the methods of science. 